\title{
Characterization of a Natural Dye by Spectroscopic and Chromatographic Techniques
}

Y. Espinosa-Morales ${ }^{1}$, J. Reyes ${ }^{1}$, B. Hermosín ${ }^{2}$, J. A. Azamar-Barrios ${ }^{3}$

${ }^{1}$ Centro de Investigación en Corrosión, Universidad Autónoma de Campeche. Avda. Agustín Melgar s/n entre Juan de la Barrera y Calle 20. Colonia Lindavista, San Francisco de Campeche, México. e-mail: javreyes@uacam.mx

${ }^{2}$ Instituto de Recursos Naturales y Agrobiología de Sevilla (IRNAS-CSIC), Spain. ${ }^{3}$ CINVESTAV-Unidad Mérida, México.

\section{ABSTRACT}

Natural dyes have been extracted from both plants and animal to give color to textiles and handicrafts. This is the case of purple dye extracted from Justicia spicigera Schldt, an acanthaceae used as a color source since pre-Hispanic period in the Mayan area of Mexico and Central America. Spectroscopic (UV-Vis and FT-IR) and chromatographic (PY-GC/MS) techniques were employed in order to characterize some of their chemical properties. UV-VIS absorption spectra indicates a $\lambda_{\max }$ peak at $581 \mathrm{~nm}$, value associated to anthocyanins group under bathochromic effect. On the other hand, a structural characterization realized by FT-IR and PyGC/MS indicated the presence of polar hydroxibenzoic acids and phenolic compounds which are characteristics of the molecular structure of anthocyanins.

\section{INTRODUCTION}

Mesoamerican culture had characterized by the use of variety of dyes extracted from natural sources like minerals, plants and animals. Dyes were employed to get color to textiles, ceramics, mural and also corporal paint for native population of America, where color had several ceremonial and quotidian contexts $[1,2]$.

In Mexico, it is highlighted the blue color extracted from añil (Indogofera Tictoria Linn). The exotic blue Maya for example, was made by mixig the extract of añil with paligoskite clay, getting high stability along the time [3].

In the Maya region of Mexico and Central America, people learned to value the use of natural sources of dyes from plants like Achiote (Bixa Orellana), Indigo, Palo de Campeche (Haematoxylum campechianun), Kanté (Diphysa robinoides Mill.) and Chak Lool (Justicia spicigera Schltd) among others [1,3]. The Spanish colonizers gave great importance to the discovery of the native species and variety of plants used as a color sources in America [4, 5].

The leaves of Chak Lool plant have been used to extract a purple dye traditionally employed for artisans from the Camino Real Region in Campeche (México), to dye textiles and handicraft like the guano palm from they get the jipi hats, bags and carpets (Figure 1a and 1b). Nowadays, there is not enough information about its chemical structure and properties. Nevertheless, it is know that purple colors produced by plants are related to the flavonoids group called anthocianins [6].

More studies are necessary in order to include the chemical properties of the Chak Lool dye extract in a Mexican color data base [7]. For this purpose, actually exist diverse spectroscopic and chromatographic techniques widely used to characterize the properties of natural compounds like colorants. 

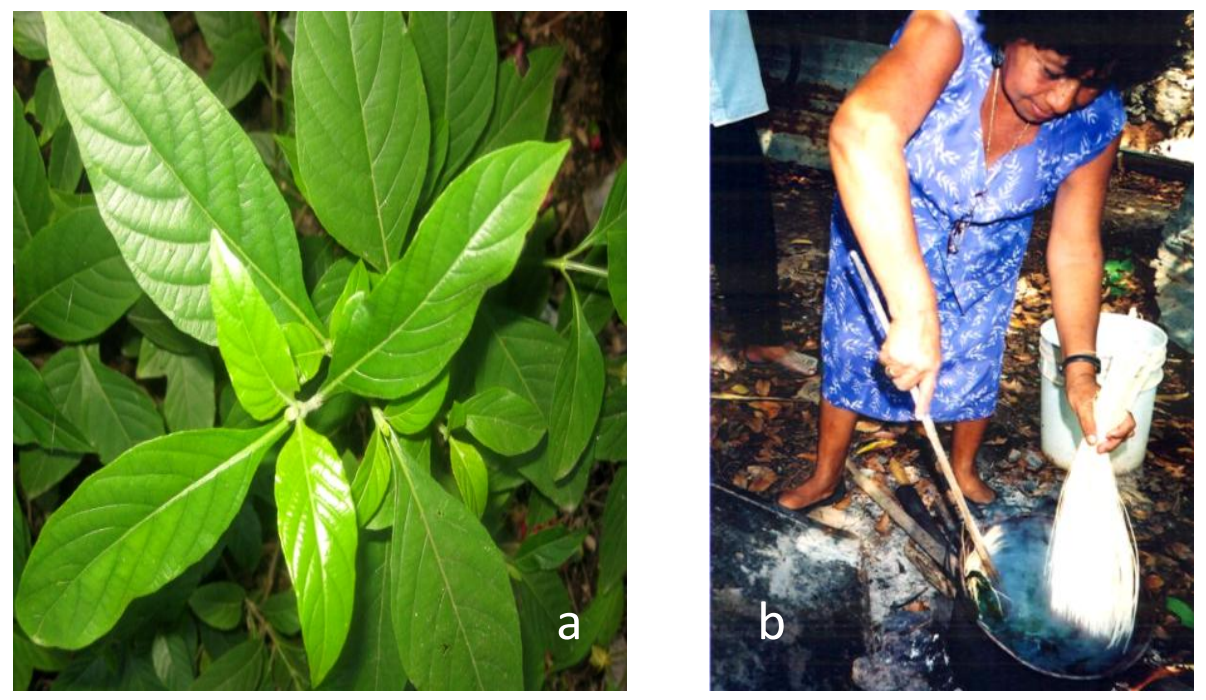

Figure 1. (a) General appearance of the leaves of Justicia Spicigera Schltdl (Chak Lool plant). (b) Artisanal purple dye extraction from Chak Lool plant.

Analytical pyrolysis coupled to gas chromatography/mass spectrometry (PY-GC/MS), is a chromatographic variant used to analyze organic matter in short time and minimum sample preparation [8]. It allows the study of biopolymers or geopolimers, and naturals products like superior plant metabolites, from the analysis and interpretation of its pyrolysis products [9-14].

On the other hand, Ultraviolet/Visible absorption (UV/VIS) and Fourier TransformedInfrared (FT-IR) spectroscopies can be used as qualitative tool to identify and characterize molecular species or some of their properties like molecular structures and characteristic absorption spectra that at least constitute their characteristic fingerprints.

This contribution shows the results of the use of these techniques in order to analyze the purple dye extracted from leaves of Chak Lool plants. The study allowed the generation of its chemical characteristic profiles and the identification of some structures probable associated to its purple color.

\section{MATERIALS AND METHODS}

\section{Obtaining the dye extract}

$5 \mathrm{~g}$ of fresh leaves from Chack Lool plant was crushed in a glass mortar and extracted with $100 \mathrm{ml}$ of the aqueous pure distilled water during one hour in an ultrasound bath (Cole Parmer). After that, the purple dye extract was filtered across $21 \mathrm{~mm}$ glass fiber membrane (GF/A, Whatman), then kept at $3^{\circ} \mathrm{C}$ protected from the direct light (Figure $2 \mathrm{a}$ ).

On the other hand, $5 \mathrm{~g}$ of leaves were dried in a convention oven at $45{ }^{\circ} \mathrm{C}$ during 24 hours and extracted following the procedures previously described. In both cases, $15 \mathrm{ml}$ of each extract was lyophilized in a Labconco freeze-dry system in order to realize FTIR and Py-GC/MS analysis (Figure $2 b$ ). 

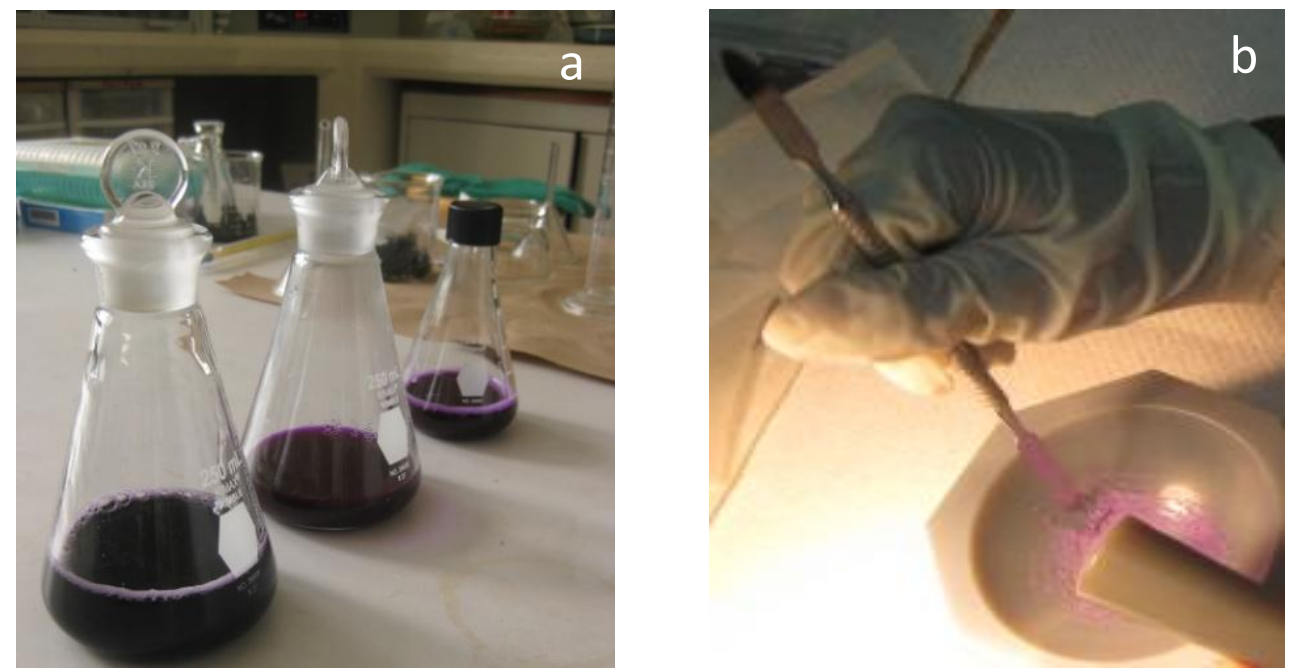

Figure 2. (a) Aqueous dye extract of obtained from leaves of Chack Lool plant. (b) Lyophilized dye extract.

\section{$\underline{\text { UV-Vis spectroscopy analysis }}$}

$1 \mathrm{ml}$ of the total aqueous dye extract was diluted in $100 \mathrm{ml}$ of pure distilled water. An aliquot was introduced in a quartz cell $(1 \mathrm{~cm}$ pathway) and analyzed in a Jenway UV/Vis spectrophotometer. A scan from 300 to $600 \mathrm{~nm}$ was performed in order to generate the characteristic absorption spectra of the sample.

\section{FT-IR spectroscopy analysis}

$5 \mathrm{mg}$ of lyophilized dye extract were mixed thoroughly with $195 \mathrm{mg}$ of potassium bromide $(\mathrm{KBr})$ until homogenized in an agate mortar. The mixture was placed into the sample compartment of a Smart Collector Diffuse Reflectance Infrared Fourier Transform Spectroscopy (DRIFTS) attachment of the spectrometer, which was continuously purged with dry air. Then, analyzed in a Thermo Nicolet Nexus 670 FT-IR spectrophotometer equipped with a DTGS KBr detector and a purge gas generator; at a spectral resolution and wave number precision of 0.09 and $0.01 \mathrm{~cm}^{-1}$ respectively. For each spectrum, 32 scans were used.

\section{$\underline{\text { PY-GC/MS analysis }}$}

A few mg of lyophilized dye extract and grinded dry leaves from Chak Lool were deposited in a separate Curie-point small hollow ferromagnetic cylinder (temperature $300^{\circ} \mathrm{C}$ ), dried and wetted with $5 \mu \mathrm{l}$ of methanolic solution of tetramethyl-amonium hydroxide $(25 \% \mathrm{w} / \mathrm{w})$. The cylinder was slightly dried with a $\mathrm{N}_{2}$ flow and immediately inserted in the pyrolyser.

The analysis was performed in a Fisons instrument GC 8000 Top/VOYAGER, using a $30 \mathrm{~m}$ x $0.25 \mathrm{~mm}$ ZB $5 \mathrm{~ms}$ column (film thickness $0.25 \mu \mathrm{m}$ ), coupled to Fischer 0316 Curie-point pyrolyser. The $\mathrm{GC}$ oven was programmed from $50^{\circ} \mathrm{C}$ to $280^{\circ} \mathrm{C}$, at a rate of $5^{\circ} \mathrm{C} \mathrm{min} \mathrm{m}^{-1}$. This temperature was held for $30 \mathrm{~min}$ and then to $310^{\circ} \mathrm{C}$ at $20^{\circ} \mathrm{C} \mathrm{min}{ }^{-1}$, where the final temperature was held for $2 \mathrm{~min}$. 
The mass detector operated at ionization energy of 70 eve, with a scan rate of $0.9 \mathrm{sec}$. The mass spectra identification was carried on by using own spectra collection and the NIST electronic library from the Unites State of America. In the analytical procedure used in this work, the carboxylic acids were recovered as the corresponding methyl esters and the hydroxyls as methoxyls.

\section{DISCUSSION}

The characteristic purple color manifested by the dye extract could be the consequence of the presence of compounds derived room anthocyanins group. Figure 3 shows the absorption spectra generated during the analysis of the aqueous dye extract obtained from leaves of Chak Loo ${ }^{1}$ nnnt

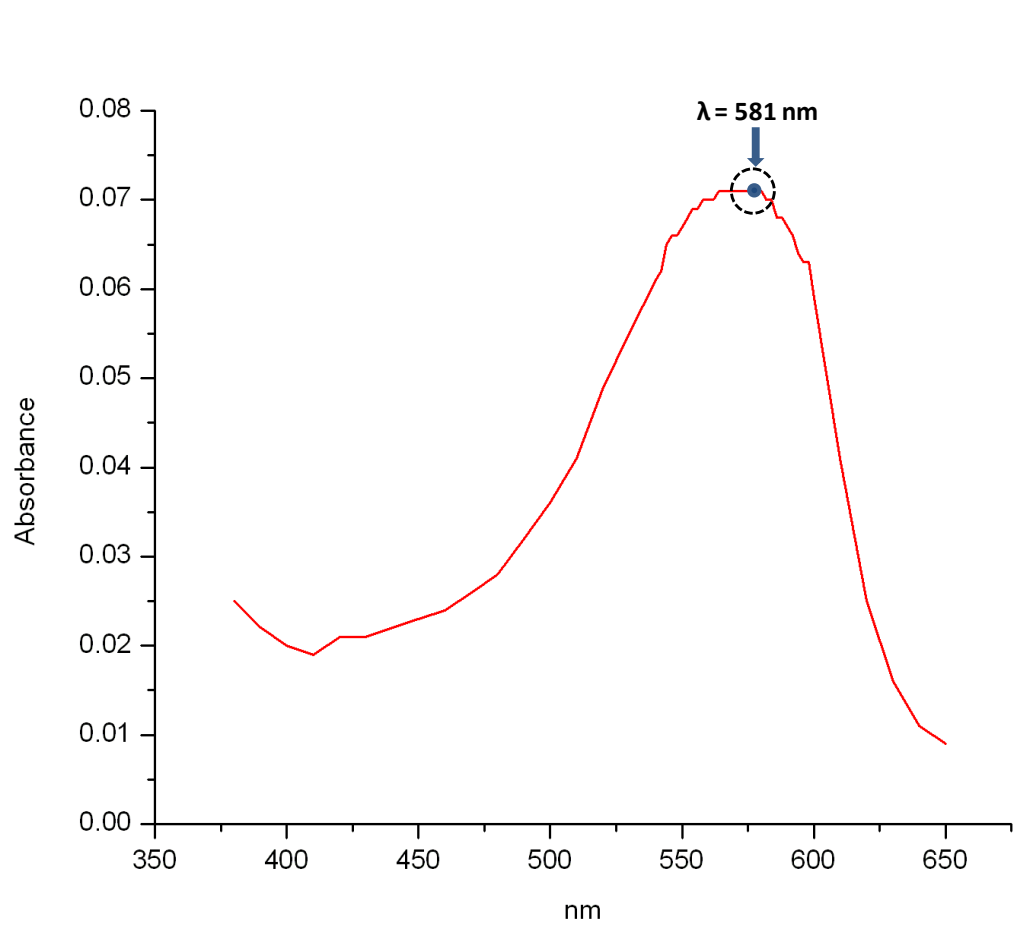

Figure 3. UV-VIS spectra from aqueous dye extract obtained from leaves of Chak Lool plant.

A maximum absorbance peak $\left(\lambda_{\max }\right)$ was detected at $581 \mathrm{~nm}$. This value does not match with those corresponding to anthocyanins like petunidin $\left(\lambda_{\max }=543 \mathrm{~nm}\right)$, malvidin $\left(\lambda_{\max }=542 \mathrm{~nm}\right)$ or delphinidin $\left(\lambda_{\max }=546 \mathrm{~nm}\right)$. This fact suggests a bathochromic effects probably caused by copigmentation mechanisms. It is consequence of a typical anthocyanins intermolecular association within flavonoids like tannins and catechins or glucocydic groups which can act like copigments.

Co-pigmentation mechanisms have been studied by several authors [15-18]. They reported that the increasing in cafeic acid concentration shift the $\lambda_{\max }$ to highest value and also increase the possibility of hyperchromic effects in anthocyanins at $\mathrm{pH}$ value between 3.0 and 4.0.

In 1915, Willstates and Mieg [19] related the red-purple color of Delphinium ajacis, with delphinidin molecule. It have been observed that when delphinidin suffer co-pigmentation, its $\lambda_{\max }$ is shifted until closer values to that observed for Chak Lool aqueous extract $\left(\lambda_{\max }=581 \mathrm{~nm}\right)$. 
They reported that an increasing in cafeic acid concentration shifts the $\lambda_{\max }$ to highest value and also increase the possibility of hyperchromic effects in anthocyanins at $\mathrm{pH}$ value between 3.0 and 4.0. Other reports indicate that during the formation of cafeic acid/delphinidin complex, $\lambda_{\max }$ value is shifted until $585 \mathrm{~nm}[16,20]$.

On the other hand, Schreiber et al. [18], observed that the complexation of delphinidin with metallic ions like $\mathrm{Al}^{3+}$ displaced $\lambda_{\max }$ even $589 \mathrm{~nm}$. Anthocyanins are water soluble nonnitrogenous phenolic compounds.

This fact suggests the apparition of a bathochromic effects probably caused by copigmentation mechanisms. Co-pigmentation mechanisms have been studied by several authors [15-18].

They are a cationic form of flavil group [21]. Its structure is formed by two aromatic groups (Figure 4): the benzopiril group ( $\mathrm{A}$ and $\mathrm{C}$ ring) and the phenolic group (B ring). Those compounds may have $\mathrm{H}$, $-\mathrm{OH}$ or $-\mathrm{OCH}_{3}$ substituent groups. Their characteristic color depends strongly from the number of substituents at the B ring (Table 1) [22].

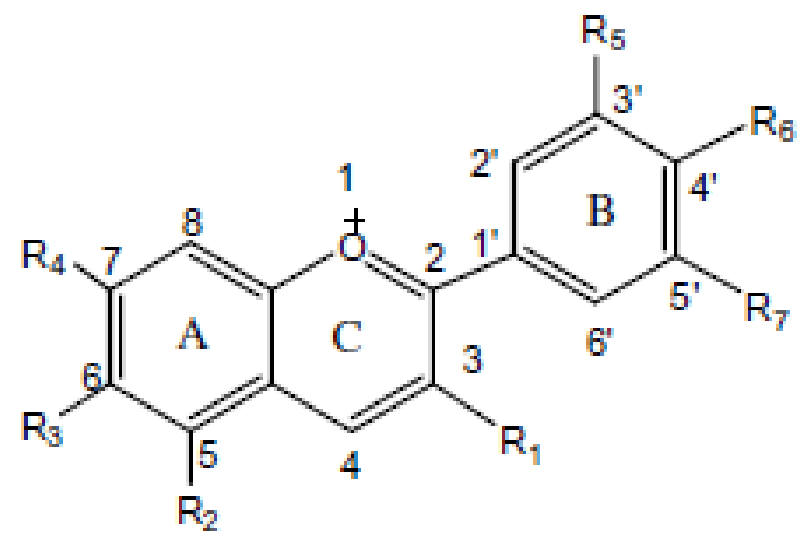

Figure 4. General structure of anthocyanins.

Table 1. Typical B ring substituent at the flavil group.

\begin{tabular}{|l|l|l|}
\hline Anthocyanins & $\mathbf{R}_{\mathbf{5}}$ & $\mathbf{R}_{\mathbf{7}}$ \\
\hline Pelargonidin & $-\mathrm{H}$ & $-\mathrm{H}$ \\
\hline Cyanidin & $-\mathrm{OH}$ & $-\mathrm{H}$ \\
\hline Delphinidin & $-\mathrm{OH}$ & $-\mathrm{OH}$ \\
\hline Petunidin & $-\mathrm{OH}$ & $-\mathrm{OCH} 3$ \\
\hline Malvidin & $-\mathrm{OCH}$ & $-\mathrm{OCH} 3$ \\
\hline Peonidin & $-\mathrm{OCH} 3$ & $-\mathrm{H}$ \\
\hline
\end{tabular}


In this order, FT-IR spectra in figure 5 of lyophilized extract shows a strong signal corresponding to the characteristic $\mathrm{C}-\mathrm{C}=\mathrm{C}$ aromatic group vibrational frequency $\left(1618-1645 \mathrm{~cm}^{-}\right.$ $\left.{ }^{1}\right)$. At $795-825 \mathrm{~cm}^{-1}$, a weak absorption band from the aromatic $\mathrm{C}-\mathrm{H}$ bond out the plane flexion movement was observed [23, 24]. Between 1405 and $1416 \mathrm{~cm}^{-1}$ the flexion movements corresponding to the phenolic - $\mathrm{OH}$ group was presented. A wide band from $\mathrm{OH}$ group was manifested in the range of $3222-3310 \mathrm{~cm}^{-1}$, while the typical vibrational frequency from C-O bond stretching movement was observed at $1233-1224 \mathrm{~cm}^{-1}$. It was an indicative of the presence of phenolic compounds in the molecular structure of the dye.

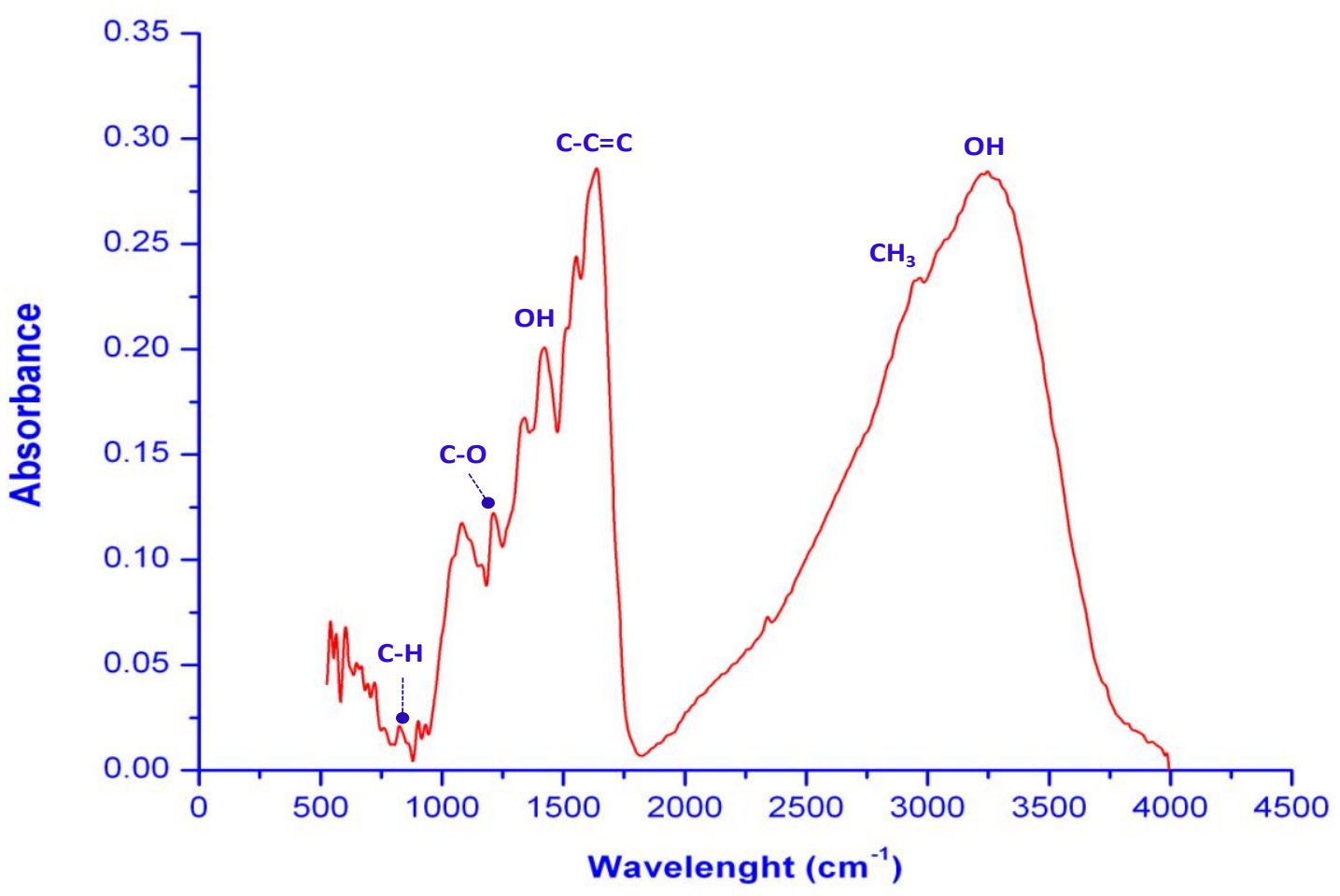

Figure 5. FT-IR spectra from lyophilized purple dye extract obtined from leaves of Chak Lool plant and associated funtional group.

On the other hand, the asymmetric movements from $-\mathrm{CH}_{3}$ group appeared in the range of 2922 to $2973 \mathrm{~cm}^{-1}$. That structure could be associated to the methoxyl- group (-OCH3), which is usually related with purple color when it is a substituent in the phenolic B ring of the flavil group of anthocyanins.

Table 2, lists the major compound identified during the PY-GC/MS analysis from both the the drye leaves and the lyophilized purple dye extracts (from fresh and dry leaves) of the Chak Lool plant.

Figure 6 shows the Total Ion Chromatogram (TIC) from their respective pyrolysates. According the results, the predominant identified structures correspond to phenolic derivatives like methoxybenzoic acids (group A), phenolic acids (group B), n-carboxilic acids (group C). Also derivatives from cellulose (group D), alkaloids (group E) and terpenoid hydrocarbons (group H) could be observed. Figure 7 shows the major structures identified. 


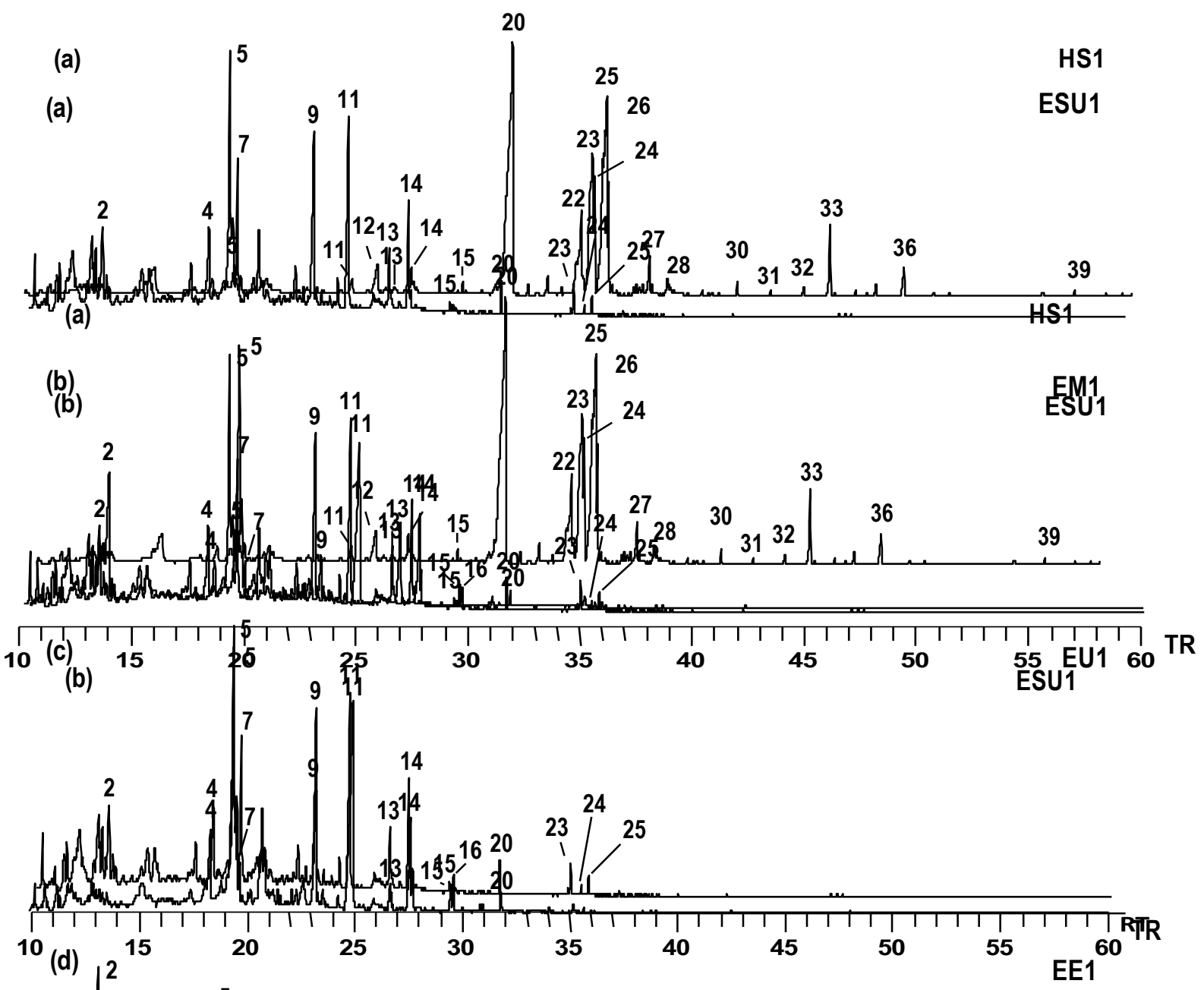

Figure 6. Total jon chromatogram (TIC) from: (a) dry leaves plant (HS1), (b) and the lyophilized purple from the 12 fry leaves (ESU1) and (c) fresh leaves (EU1) of Chak Lool. RT, Retention Time (minutes).

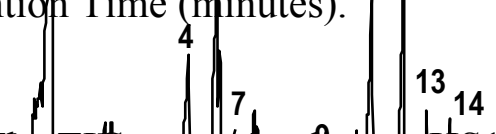

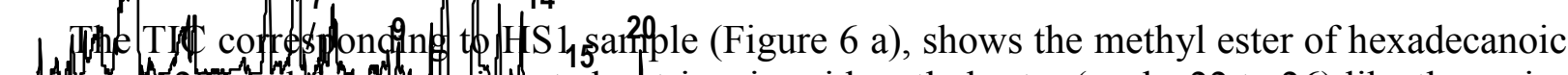

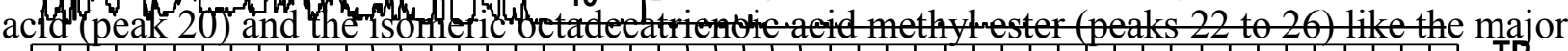

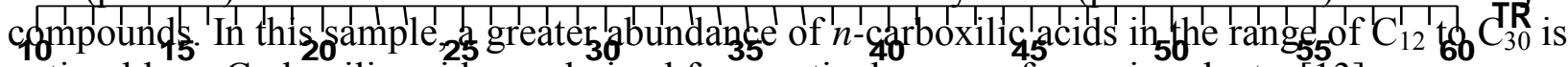
noticeable. $n$-Carboxilic acids are derived from cuticular wax of superior plants [13].

It was noticeable the relative high intensity of the peak 33, that corresponded to the acyclic isoprenoid hydrocarbon squalene $(2,5,10,15,19,23$-hexametyl tetracosane), that is precursor of polycyclic triterpenoids in animals and plants. This compound was isolated for first time in shark liver oil [25]. Recently, its presence was reported in chromatographic profiles of melastomataceae plants [26]. Phenolic and methoxybenzoic groups appear only as minor compounds within the furanone 4-methoxy-2,5-dimethyl-3(2H)-furanone (peak 3 ) and the alkaloid 3-methoxycarbazol (peak 12). 
Table 2. Major compounds identified during the PY-GC/MS analysis of the dry leaves (HS1) and the lyophilized purple dry extract from fresh leaves (EU1) and, dry leaves (ESU1) of Chak Lool Plant. (+) identified, (-) not identified.

\begin{tabular}{|c|c|c|c|c|c|}
\hline Peak & Compounds & Group & HS1 & ESU1 & EU1 \\
\hline 1 & Benzoic acid, methyl ester & B & - & + & . \\
\hline 2 & 1,4-Dimethoxy benzene & A & + & + & + \\
\hline 3 & 4-Methoxy-2,5-dimethyl-3(2H)-furanone & D & + & - & - \\
\hline 4 & 3-Methoxy benzoic acid, methyl ester & B & + & + & + \\
\hline 5 & 1,2,4-Trimethoxy benzene & A & + & + & + \\
\hline 6 & 4-Methoxy benzoic acid, methyl ester & B & + & + & + \\
\hline 7 & 3-Phenyl-2-propenoic acid, methyl ester & B & + & + & + \\
\hline 8 & 1,2,3-Trimethoxy-5-methyl-benzene & A & - & + & + \\
\hline 9 & 1,2,3,4-Tetramethoxy benzene & A & - & + & + \\
\hline 10 & Dodecanoic acid, methyl ester & C & - & + & + \\
\hline 11 & 3,4-Dimethoxy benzoic acid, methyl ester & B & + & + & + \\
\hline 12 & 3-Methoxy-9H-carbazole & E & + & $\cdot$ & $\cdot$ \\
\hline 13 & 3-(4-methoxyphenyl)-2-propenoic acid, methyl ester & B & + & + & + \\
\hline 14 & Tetradecanoic acid, methyl ester & C & + & + & + \\
\hline 15 & 3,4,5-Trimethoxy benzoic acid, methyl ester & B & + & + & + \\
\hline 16 & 3-Ethyl-2-phenyl indole & E & - & - & + \\
\hline 17 & 3-Allyl-1,4-dimethoxy carbazole & E & - & - & + \\
\hline 18 & Pentadecanoic acid, methyl ester & C & + & + & + \\
\hline 19 & 3-(3,4-Dimethoxyphenyl)-2-propenoic acid, methyl ester & B & - & - & + \\
\hline 20 & Hexadecanoic acid, methyl ester & C & + & + & + \\
\hline 21 & Heptadecanoic acid, methyl ester & C & + & - & - \\
\hline 22 & Octadecatrienoic acid, methyl ester & C & + & $\cdot$ & - \\
\hline 23 & Octadecatrienoic acid, methyl ester & C & + & - & - \\
\hline 24 & Octadecanoic acid, methyl ester & C & + & + & + \\
\hline 25 & Octadecatrienoic acid, methyl ester & C & + & - & - \\
\hline 26 & Octadecadienoic acid, methyl ester & C & + & - & - \\
\hline 27 & $9,12,15-0$ ctadecatrienoic acid, methyl ester & C & + & $\cdot$ & - \\
\hline 28 & Eicosanoic acid, methyl ester & C & + & - & - \\
\hline 29 & Heneicosanoic acid, methyl ester & C & + & - & - \\
\hline 30 & Docosanoic acid, methyl ester & C & + & $\cdot$ & - \\
\hline 31 & Tricosanoic acid, methyl ester & C & + & - & $\cdot$ \\
\hline 32 & Tetracosanoic acid, methyl ester & C & + & - & - \\
\hline 33 & Squalene & H & + & - & $\cdot$ \\
\hline 34 & Pentacosanoic acid, methyl ester & C & + & - & - \\
\hline 35 & Hexacosanoic acid, methyl ester & C & + & - & - \\
\hline 36 & Heptacosanoic acid, methyl ester & C & + & - & - \\
\hline
\end{tabular}


Figures $6 \mathrm{~b}$ and $6 \mathrm{c}$ show the TIC from the lyophilized purple dye extract (ESU1) and fresh leaves (EU1) from Chak Lool plant. Figure 7 shows the most important structures of phenolic and carboxylic acids peak compounds identified in the pyrolysates. In both cases, aqueous extraction allowed the preferential separation of the most polar compounds present in leaves, like phenolic compounds and its methoxy- and carboxylic derivatives.

The last one coincides with FT-IR spectroscopic characterization realized to EU1 samples. $n$-Carboxylic acid are only separated on trace levels under $\mathrm{C}_{20}$, while compounds like squalene or furanones were not extracted. Majority compounds included 1,2,3-trimethoxybenzene (peak 5), 1,2,3,4-tetramethoxybenzene (peak 9) and 2,4-dimethoxybenzoic acid methyl ester (peak 11). Other compounds also separated were 3-phenyl-2-propenoic acid methyl ester and 3-(3,4methoxyphenyl)-2-propenoic acid methyl ester (cafeic acid) corresponding to structures labeled as peaks 7,13 and 19 respectively (Figure 7).

It is important to highlight that ESU1 such as EU1 showed the same chromatographic profile, because of that, molecular structure content in both samples could be considered the dye fingerprints.

Diverse authors have related these structures with flavonoid compounds constituents of anthocyanins like cyanidin, pelargonidin or peonidin [9, 21,27]. Other authors also reported their presence in tannins and lignins [28, 29]. On the other hand, the identification of cafeic acid (structure of the peak 19) reinforce the idea of the probably apparition of co-pigmentation. That leads the shift of anthocyanins color associated $\lambda_{\max }$ until higher values such as was observed in the absorption spectra of the dye.

\section{CONCLUSIONS}

UV-Vis spectroscopy allowed the generation of the characteristic absorption spectra from the aqueous purple dye extract from leaves of Chak Lool plant. A $\lambda_{\max }$ at $581 \mathrm{~nm}$ was established. This value seems to be consequence of bathochromic effect caused by a probably co-pigmentation mechanisms induced by the presence of compounds like cafeic acid.

FT-IR analysis allowed the identification of functional groups that correspond to phenolic compounds associated to $-\mathrm{CH}_{3},-\mathrm{H}$ and $-\mathrm{OCH}_{3}$ group. They are characteristic substituent of the anthocyanins group.

A characteristic PY-GC/MS pattern was obtained from the lyophilized extract of Chak Lool plant. The analysis of the pyrolisates revealed the presence of polar compounds like hydroxibenzoic acids and phenolic compounds closely related to the structure of anthocyanins. They are probably the responsible of the characteristic purple color observed in the aqueous dye extract obtained from the leaves of Chak Lool plant. Finally the chemical structures identified the analysis of the purple dye extract obtained from leaves of Chak Lool Lool, could be considered its Fingerprint.

\section{ACKNOWLEDGMENTS}

This contribution was possible thanks to the support of the project "Extraction of natural dyes with potential application to restoration of artistic and historic works" from Universidad Autonoma de Campeche. 


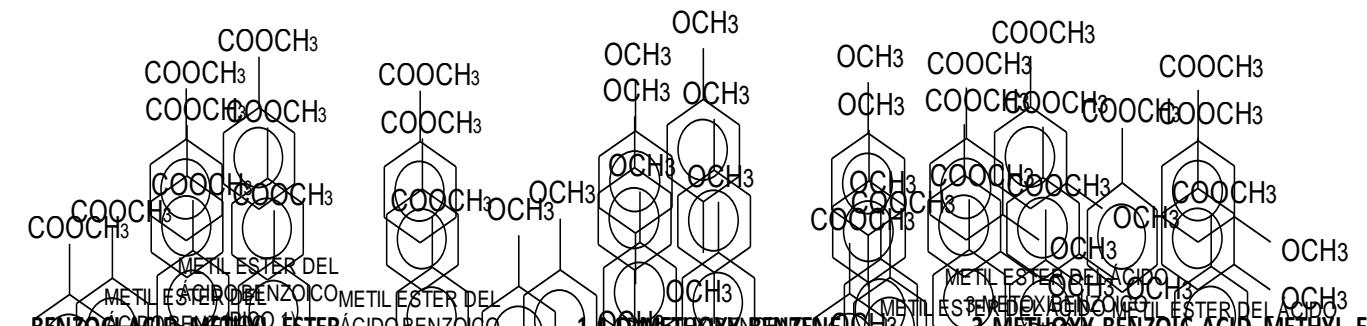

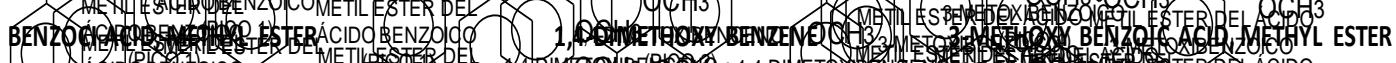

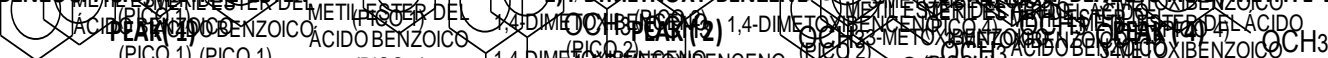

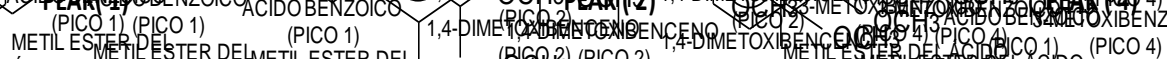

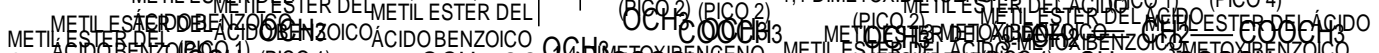

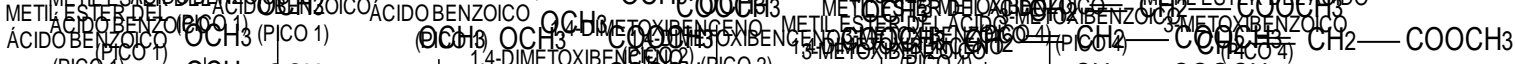

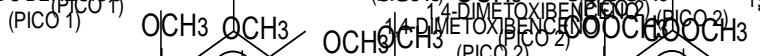

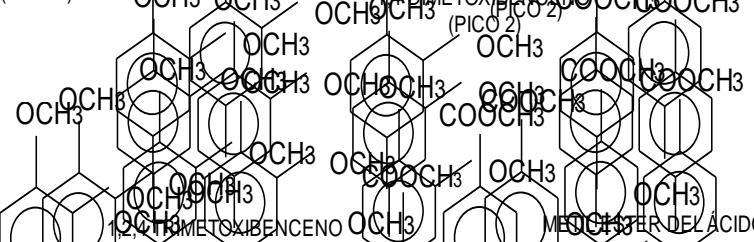

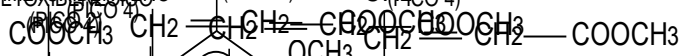

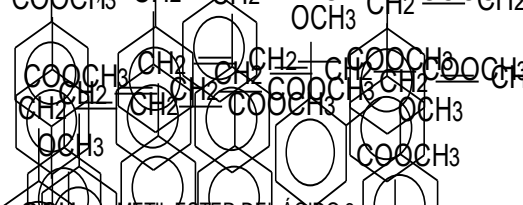

$\mathrm{COOCH}$

$\mathrm{COOCH}_{3}$

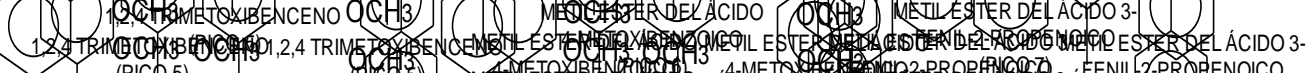

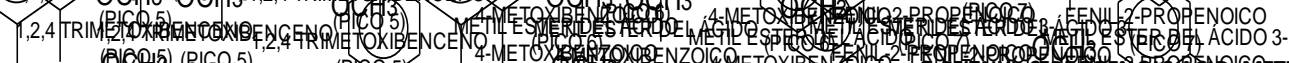

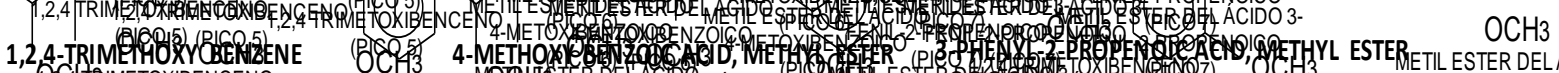

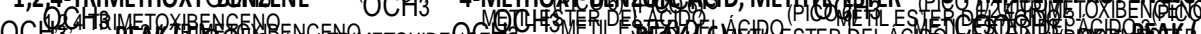

OCHY3

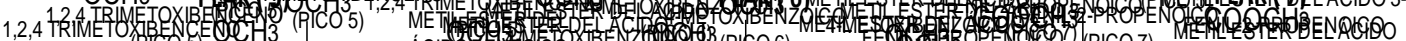

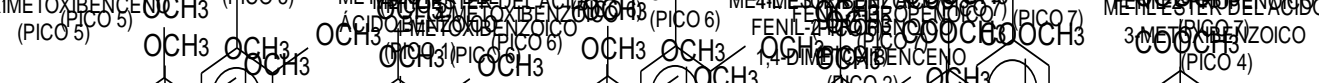

(PICO6)

2.

OCH3

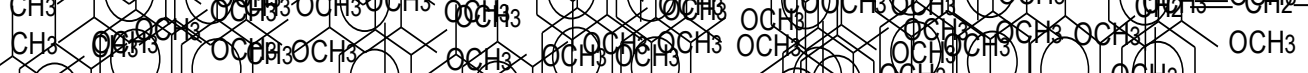

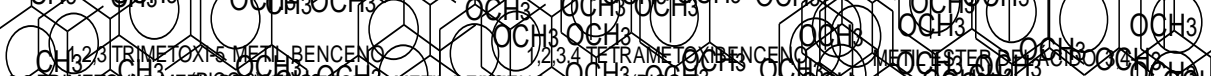

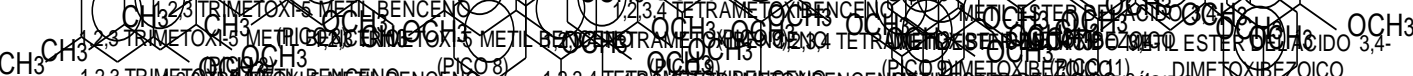

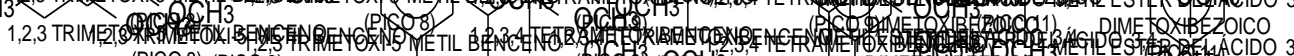

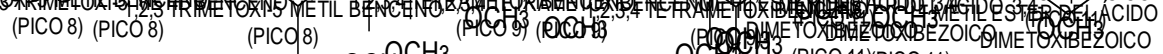

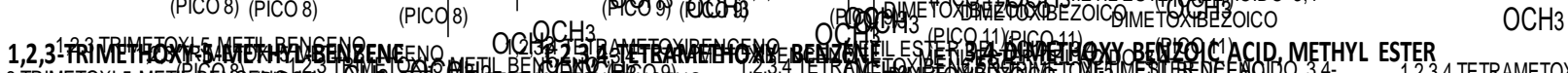

$\mathrm{OCH} 3$

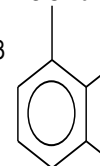

(PICO 9)

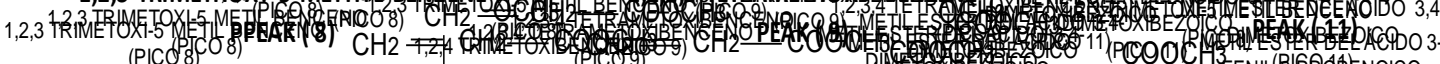

(PICO8CO8) $\mathrm{CH}_{2}=24 \mathrm{CH}$ $\mathrm{CH}_{2}=\mathrm{CH}_{2}$

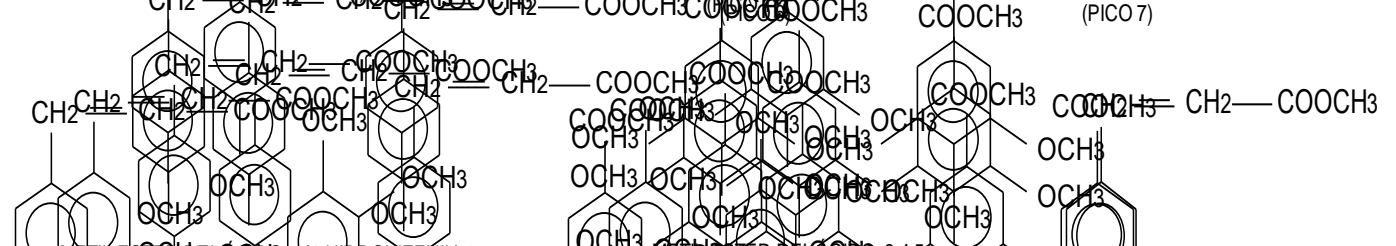

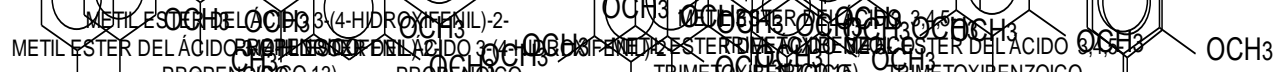

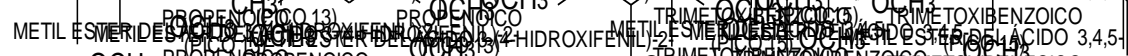

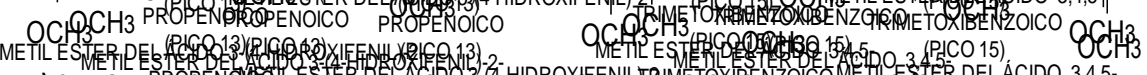

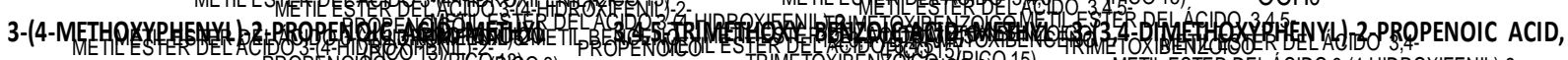

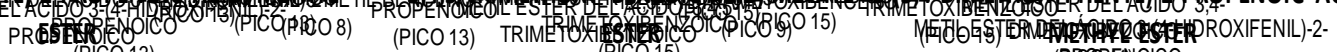

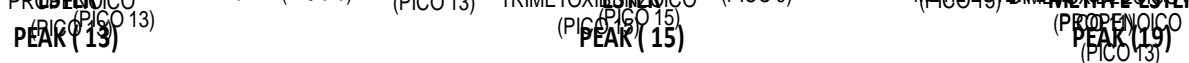

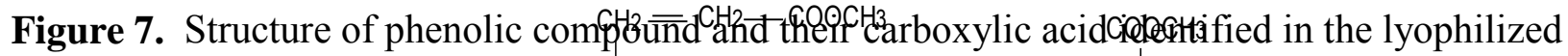
purple dye extract from dried and fresh leaves of Chack Lool plant.
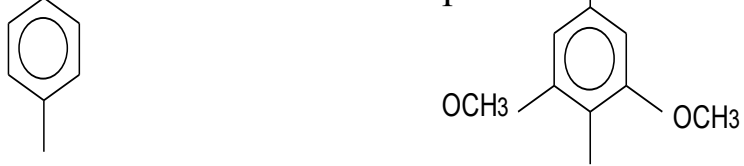


\section{REFERENCES}

1. M. Ivic, M. Berguer. in: Ciencia y técnica maya. M. Ivic de Monterroso, I. Azurdia Bravo, Ed., 2008, 101-133.

2. D. Magaloni. Arqueología Mexicana 93, (2008) 46-50.

3. D. Magaloni, in La pintura mural prehispánica en México: Área Maya. B. de la Fuente Ed., Instituto de Investigaciones Estéticas UNAM, Mexico, 2001, 155-198.

4. H. Cabezas. Unidad geográfica cultural: flora mesoamericana. Universidad Mesoamericana, Guatemala, 2005.

5. O. Lock, in: Colorantes naturales. Fondo Editorial. Pontificia Universidad Católica de Perú, Lima, 1997.

6. Y. Espinosa-Morales. Dissertation thesis. College of Chemistry and Biological Sciences. Universidad Autonoma de Campeche, Campeche, 2010.

7. E. Arroyo , T. Falcón, E. Hernández, S. Zetina, A. Nieto, J.L. Ruvalcaba. XVI Century Colonial Panel Paintings from New Spain: Material Reference Standards and Non Destructive Analysis for Mexican Retablos. 9th International Conference on NDT of Art, ART2008, Jerusalem, Israel (2008).

8. C. Saíz-Jimenez, K. Haider, H. L. C. Meuzelaar. Geoderm. 22 (1979) 25-37.

9. G. Lanzarini, L. Morselli, G.P. Pifferi, A.G. Giumanin. J. Chrom. 130 (1997) 261-266.

10. W. J. Irwin J. Anal. Appl. Py. 1 (1979) 3-25.

11. S. Ghosal, S Banerjee, D. Jaiswal. Phytochem. 19 (1980) 332-334.

12. C. Saiz-Jimenez, B. Hermosin, J. J. Ortega-Calvo. Int. J. Environ. Anal. Chem. 56 (1994) 6371.

13. J. Reyes, Doctoral thesis. School of Chemistry. Universidad de Sevilla, Sevilla, 2004, 21-23.

14. F. Shadkami, R. J. Helleur, R. M. Cox, J. Chem. Ecol. 33 (2007) 1467-1476.

15. S. Asen, R.N Sterwart., K. H Norris. Phytochem. 11(3) (1972) 1139-1144.

16. E. Gris, A. Ferrari, L. Falcao, M. Bordignon, Food Chem. (2007) 1289-1296.

17. P. A. Kanakis, M. G. Tarantilis, S Poliss, H. A Diamantoglou, Tajmir-Riahi. J. Mol. Struc. 798 (2006) 69-74.

18. H. Schreiber, A. M. Swink, T. D Godsey. J. Inorg. Biochem. 104 (2010)732-739.

19. R. Willstater, W. Mieg Liebig. Ann Chem. 408 (1915) 327.

20. K. Yoshimata, K. Hayashi. Biol. Mag. Tokio. 87 (1974) 33-40.

21. I. Guerrero, E. Lopez, R. Armenta. Pigmentos. in: Quimica de los Alimentos. Salvador Badui Ed. Fourth Edition. volume II, Pearson Educacion, México, 2006, 401-439.

22. R. Myjavcová, P. Marhol, V. Kren, V. Simanek, J. Ulrichová, I. Palíková, B. Papouskova, K. Lemr, P. Bedñar, J. of Chrom A 1217 (2010) 7932-7941.

23. A.K. Satapathy, G. Gunasekaran, S.C. Sahoo, K. Amit, P.V. Rodrigues, Corros. Sci. 51 (2009) 2848-2856.

24. O. Torres, G. Santafé, A. Angulo, H. Villa, J. Zuluaga, M. Doria. Sci. Tech. XIII 3 (2007) 333-336.

25. R. P. Phillip, Applications and spectra. Elsevier, Amsterdam, 1985, 88-91.

26. J. H. Isaza, L. M. Orozco, L. M. Zuleta, D. A. Rivera, L. J. Tapias, L. A. Veloza, L. S. Ramirez. Sci. Tech. XIII 33 (2007) 359-362.

27. Z. Füzfai, I. Molnár-Perl. J. Chrom. A 1149 (2007) 88-101.

28. C. G.Nolte, J. J. Schauer, G. R. Cass, , B. R. T. Smoneit. Environ. Sci. Tech. 35 (2001)1912-1919.

29. M. P.Fernández, P. A.Watson, C. Breuil, J. Chrom. A. 922 (2001) 225-233. 